\title{
Increased survival and deteriorating developmental outcome in 23 to 25 week old gestation infants, 1990-4 compared with 1984-9
}

\author{
H C A Emsley, S P Wardle, D G Sims, M L Chiswick, S W D’Souza
}

\begin{abstract}
Aims-To assess whether changes in survival over time in infants of 23 to 25 weeks of gestational age were accompanied by changes in the incidence of disability in childhood during an 11 year period.

Methods-Obstetric and neonatal variables having the strongest association with both survival to discharge from a regional neonatal medical unit and neurodevelopmental disability in 192 infants of 23 to 25 weeks of gestation, born in 1984 to 1994, were studied as a group and in two cohorts $(1984$ to $1989 \mathrm{n}=96$ and 1990 to $1994 \mathrm{n}=$ 96). The data collected included CRIB (clinical risk index for babies) scores and cranial ultrasound scan findings. The children were followed up at outpatient clinics.
\end{abstract}

Results-Between 1984 and 1989 (cohort 1) and 1990 and 1994 (cohort 2) the rate of survival to discharge increased significantly from $27 \%$ to $42 \%$ and the rate of disability in survivors increased from $38 \%$ to $68 \%$; most of this increase was in mild disability. The proportions of survivors with cerebral palsy did not alter significantly $(21 \%$ vs $18 \%)$, but more survivors with blindness due to retinopathy of prematurity ( $4 \%$ vs $18 \%)$, myopia ( $4 \%$ vs $15 \%)$ and squints $(8 \%$ vs $13 \%)$ contributed to the increased rate of disability. Clinically significant cranial ultrasound findings and a high CRIB score were strongly associated with death. A high CRIB score was most strongly associated with disability.

Conclusions-The rise in disability with improved survival was not due to cerebral palsy; rather the main contributors were blindness due to retinopathy, myopia, and squint. The causes of these disabilities seem to be linked to high CRIB scores. A system of regular and skilled retinal examination and access to facilities for retinal ablation should be in place in all neonatal units which undertake the care of such extremely preterm infants.

(Arch Dis Child Fetal Neonatal Ed 1998;78:F99-F104)

Keywords: survival; neurodevelopmental disability; CRIB scores; blindness; extremely preterm infants

Many studies have shown that infants born at 23 to 25 weeks of gestation now stand a much better chance of surviving than they did a decade ago. ${ }^{1-4}$ However, the principal purpose of neonatal intensive care is to promote intact survival. There is concern that improvements in survival rates of infants born close to the limits of viability simply allow those who have already sustained cerebral damage in the womb to survive. Even if they are born undamaged, there is the worry that their struggle for survival might expose them to a range of damage provoking insults which culminate in childhood disability. ${ }^{4-10}$

Inevitably there is a trade off whereby survival is achieved at the expense of disability in childhood, but there are few data available on how this trade off might change over time under the influence of new methods of intensive care, and on a shift in treated neonates towards even lower gestations.

In parallel with the advances made in neonatal intensive care, scoring systems for the assessment of neonatal risk have been developed. The CRIB (clinical risk index for babies) score ${ }^{11}$ was developed to provide a better way of comparing the performance of different hospitals in neonatal intensive care. The CRIB score is also more accurate than birthweight alone in predicting subsequent disability, ${ }^{12}$ but this may have changed, with increasing survival rates. ${ }^{13-15}$

We present mortality and follow up data on 192 infants born at 23 to 25 weeks of gestation during an 11 year period which was punctuated by the introduction of antenatal steroids, surfactant therapy, and a shift towards much lower gestational ages at birth. All surviving infants have been accounted for and followed up. The main purpose was to assess whether changes in survival rates with time were accompanied by a change in the incidence of disability in childhood, and, if so, the nature of any trends, and the influencing factors.

\section{Methods}

Annual surveys (1984 to 1994) have provided information on all births in hospitals within the North Western Region, including St Mary's Hospital which provides a regional neonatal intensive care service (Maternities and Infants in the North Western Region 1984 to 1991, Information Analysis Department, North West Regional Health Authority, Manchester; and North Western Perinatal Survey and Confidential Enquiry into Stillbirths and Deaths in Infancy 1992 to 1994, A J Barson and JA Sands, St Mary's Hospital, Manchester). Table 1 shows the total number of births, stillbirths, and live births in infants weighing less than 1.0 $\mathrm{kg}$ in this region and infants of 23 to 25 weeks gestational age admitted to our neonatal medical unit in two eras, 1984 to 1989 and 1990 to 1994. 
Table 1 Extremely low birthweight infants born in North Western Regional Hospitals, including St Mary's Hospital, 1984-94

\begin{tabular}{lcc}
\hline & $1984-89$ & $1990-94$ \\
\hline $\begin{array}{l}\text { North Western Region birthweights < 1.0 kg: } \\
\text { Total births }\end{array}$ & 1446 & 1448 \\
Stillbirths & $349(24 \%)$ & $322(22 \%)$ \\
Livebirths & $1097(76 \%)$ & $1135(78 \%)$ \\
23-25 weeks' gestational age, admitted to St Mary's & $96(7 \%)$ & $96(7 \%)$ \\
neonatal unit & & \\
St Mary's Hospital gestational age 23-25 weeks: & $138(32 \%)$ & $19(22 \%)$ \\
Total births & $44(68 \%)$ & $69(78 \%)$ \\
Stillbirths & $37(27 \%)$ & $5(6 \%)$ \\
Livebirths & $57(41 \%)$ & $64(72 \%)^{\star \star \star \star \star}$ \\
Deaths before admission to neonatal unit &
\end{tabular}

Percentage of total births is shown in parentheses.

Levels of significance: ${ }^{\star \star \star \star} \mathrm{p}<0.0001$.

Regional data were not available by gestational age, so we made the assumption that birthweights of less than $1.0 \mathrm{~kg}$ would include all infants at 23 to 25 weeks of gestational age. In those infants admitted to the unit at our hospital, gestational age was estimated as the number of completed weeks from the first day of the last menstrual period. In each infant this was compared with assessment of gestational age by ultrasonography, if a scan had been carried out by 20 weeks of gestational age. The scan assessment was preferred if the gestational age estimated differed by more than 14 days from that estimated from menstrual dates. ${ }^{6}$ The study population, which was divided into two periods

Table 2 Obstetric and neonatal conditions

\begin{tabular}{|c|c|c|c|}
\hline & $\begin{array}{l}\text { Cohort } 1(1984-89) \\
n=96\end{array}$ & $\begin{array}{l}\text { Cohort } 2(1990-94) \\
n=96\end{array}$ & $\begin{array}{l}\text { Total (1984-94) } \\
n=192\end{array}$ \\
\hline Maternal age (years) & $26.7(6.0)(93)$ & $27.1(6.1)(90)$ & $26.9(6.0)(183)$ \\
\hline $\begin{array}{l}\text { Premature rupture of } \\
\text { membranes }\end{array}$ & $26 / 93(28 \%)$ & $23 / 89(26 \%)$ & $49 / 182(27 \%)$ \\
\hline $\begin{array}{l}\text { Prolonged rupture of } \\
\text { membranes }\end{array}$ & $19 / 93(20 \%)$ & $18 / 89(20 \%)$ & $37 / 182(20 \%)$ \\
\hline Antenatal steroids & $0(-)$ & $22(23 \%)^{\star \star \star \star \star}$ & $22(11 \%)$ \\
\hline Caesarean section & $10(10 \%)$ & $18(19 \%)$ & $28(15 \%)$ \\
\hline Inborn & $57(59 \%)$ & $64(67 \%)$ & $121(63 \%)$ \\
\hline Multiple pregnancy & $24(25 \%)$ & $32(33 \%)$ & $56(29 \%)$ \\
\hline Male:female ratio & $2: 1$ & $1.2: 1$ & $1.65: 1$ \\
\hline Birthweight $(\mathrm{g})$ & $751.7(126.9)$ & $697.1(127.2)^{\star \star}$ & $725.0(129.6)$ \\
\hline Gestational age (weeks) & $24.5(0.6)$ & $24.2(0.7)^{\star \star}$ & $24.4(0.7)$ \\
\hline CRIB score & $11.1(4.8)$ & $10.8(4.4)$ & $10.9(4.6)$ \\
\hline Surfactant & $0(-)$ & $52(54 \%)^{\star \star \star \star}$ & $52(27 \%)$ \\
\hline $\begin{array}{l}\text { Significant cranial ultrasound } \\
\text { finding }\end{array}$ & $4 / 75(59 \%)$ & $30 / 76(40 \%)^{\star}$ & $74 / 151(49 \%)$ \\
\hline
\end{tabular}

Results are mean (SD). Number of observations, or percentages are shown in parentheses. Levels of significance: ${ }^{\star} \mathrm{p}<0.05,{ }^{\star \star} \mathrm{p}<0.01,{ }^{\star \star \star \star} \mathrm{p}<0.0001$.

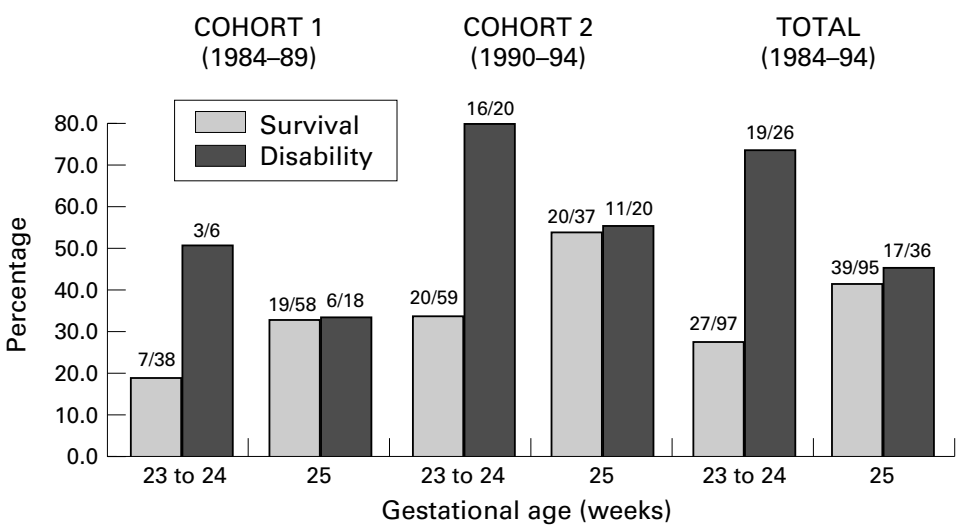

Figure 1 Survival to discharge and disability by gestational age. Numbers of 23 and 24 week old gestational age infants are shown in tables 3 and table 5.
- A significant improvement in survival was not accompanied by an increase in the rate of cerebral palsy

- High CRIB scores and major ultrasound abnormalities predicted death and survival with disability

- The prevalence of disability caused by visual problems, including retinopathy of prematurity increased significantly

by date of birth, 1984 to 1989 (cohort 1) and 1990 to 1994 (cohort 2), by chance, contained an equal number of infants in each cohort $(\mathrm{n}=$ 96).

Table 1 further shows the total number of births, stillbirths, live births and deaths before admission to the unit at St Mary's Hospital at 23 to 25 weeks gestational age. In cohort 1, 57 infants were born at St Mary's Hospital and 39 infants were transferred in from other hospitals. In cohort 2, 64 infants were born at St Mary's Hospital and the remaining 32 were from other hospitals. The proportions of inborn to outborn infants were therefore similar in these two cohorts which were compared with respect to survival and outcome in childhood and the influence of obstetric and neonatal variables. All surviving infants were followed up at outpatient clinics at St Mary's Hospital, or at a hospital near to their place of residence. The duration of follow up ranged from 19 months to 10 years 7 months.

Obstetric and neonatal data were obtained retrospectively from the case notes. The obstetric variables recorded included the following: maternal age in years; place of birth recorded as inborn or outborn (three infants born in transit to St Mary's Hospital, were coded as outborn); prolonged rupture of membranes (more than 24 hours before onset of labour); premature rupture of membranes (rupture of membranes before labour); caesarean section; and multiple pregnancy (twins and triplets). Neonatal variables included the following: gender; birthweight; gestational age; cranial ultrasound findings; and CRIB score. ${ }^{11}$ Clinically significant ultrasound abnormality was defined as intraventricular haemorrhage (IVH) with ventricular dilatation, parenchymal haemorrhage, cystic periventricular leucomalacia or hydrocephalus. The CRIB score was determined from birthweight, gestational age, presence or absence of congenital malformations, maximum base excess in the first 12 hours, minimum appropriate $\mathrm{FIO}_{2}$ in the first 12 hours and maximum appropriate $\mathrm{FIO}_{2}$ in the first 12 hours, according to the International Neonatal Network. ${ }^{11}$ Follow up data were recorded at each outpatient attendance at clinics and assessments carried out in the departments of audiology, ophthalmology, psychology and physiotherapy. Outcome data included infant survival until discharge from hospital, whether or not the infant survived subsequent to leaving hospital, the presence or absence of cerebral palsy, fits, hydrocephalus treated with shunt surgery, blindness (due to 
Table 3 Conditions associated with survival

\begin{tabular}{|c|c|c|c|c|c|c|}
\hline & \multicolumn{2}{|c|}{ Cohort 1 (1984-89) } & \multicolumn{2}{|c|}{ Cohort 2 (1990-94) } & \multicolumn{2}{|l|}{ Total (1984-94) } \\
\hline & $\begin{array}{l}\text { Survivors } \\
(n=26)\end{array}$ & $\begin{array}{l}\text { Non-survivors } \\
(n=70)\end{array}$ & $\begin{array}{l}\text { Survivors } \\
(n=40)\end{array}$ & $\begin{array}{l}\text { Non-survivors } \\
(n=56)\end{array}$ & $\begin{array}{l}\text { Survivors } \\
(n=66)\end{array}$ & $\begin{array}{l}\text { Non-survivors } \\
(n=126)\end{array}$ \\
\hline \multicolumn{7}{|c|}{ Gestational age (weeks): } \\
\hline 23 & $0(-)$ & $6(8 \%)$ & $3(7 \%)$ & $13(23 \%)$ & $3(5 \%)$ & $19(15 \%)$ \\
\hline 24 & $7(27 \%)$ & $25(36 \%)$ & $17(43 \%)$ & $26(46 \%)$ & $24(36 \%)$ & $51(41 \%)$ \\
\hline 25 & $19(73 \%)$ & $39(56 \%)$ & $20(50 \%)$ & $17(31 \%)$ & $39(59 \%)$ & $56(44 \%)$ \\
\hline Male sex & $13(50 \%)$ & $50(71 \%)$ & $17(43 \%)$ & $33(59 \%)$ & $40(61 \%)$ & $83^{\star}(66 \%)$ \\
\hline Birthweight & $770.3(110.5)$ & $745.5(132.5)$ & $741.0(127.4)$ & $667.6^{\star \star}(119.3)$ & $753.1(120.7)$ & $710.9^{\star}(132.1)$ \\
\hline CRIB score & $\begin{array}{l}7.6(3.9) \\
(21)\end{array}$ & $\begin{array}{l}12.5^{\star \star \star}(4.4) \\
(55)\end{array}$ & $\begin{array}{l}7.8(3.5) \\
(30)\end{array}$ & $\begin{array}{l}12.9^{\star \star \star}(3.7) \\
(42)\end{array}$ & $\begin{array}{l}7.7(3.7) \\
(51)\end{array}$ & $\begin{array}{l}12.6^{\star \star \star}(4.1) \\
(97)\end{array}$ \\
\hline \multicolumn{7}{|c|}{ Cranial ultrasound findings: } \\
\hline Significant & $9(38 \%)$ & $35^{\star}(70 \%)$ & $9(24 \%)$ & $21^{\star}(54 \%)$ & $18(30 \%)$ & $56^{\star \star \star}(63 \%)$ \\
\hline Non-significant & 15 & 15 & 28 & 18 & 43 & 33 \\
\hline
\end{tabular}

Results are numbers of children or mean (SD). Levels of significance ${ }^{\star} \mathrm{p}<0.05,{ }^{\star \star} \mathrm{p}<0.01$, $^{\star \star \star} \mathrm{p}<0.001$. Numbers of observations or percentages are shown in parentheses.

retinopathy of prematurity) or other visual impairment, deafness $(>70 \mathrm{~dB})$ and developmental delay (developmental quotient < 70). ${ }^{16}{ }^{17}$ An overall assessment of disability was made according to Cooke $^{8}$ : normal (no clinically apparent developmental abnormality causing functional disability); mild disability (myopia, language delay, mild hearing loss, hyperactivity or clumsiness); moderate disability (spastic diplegia, hemiplegia, or moderate learning disability (developmental quotient 50-69)); or severe disability (spastic quadriplegia, blindness, deafness ( $>70 \mathrm{~dB})$, uncontrolled epilepsy or severe learning disability (developmental quotient <50) and multiple disabilities).

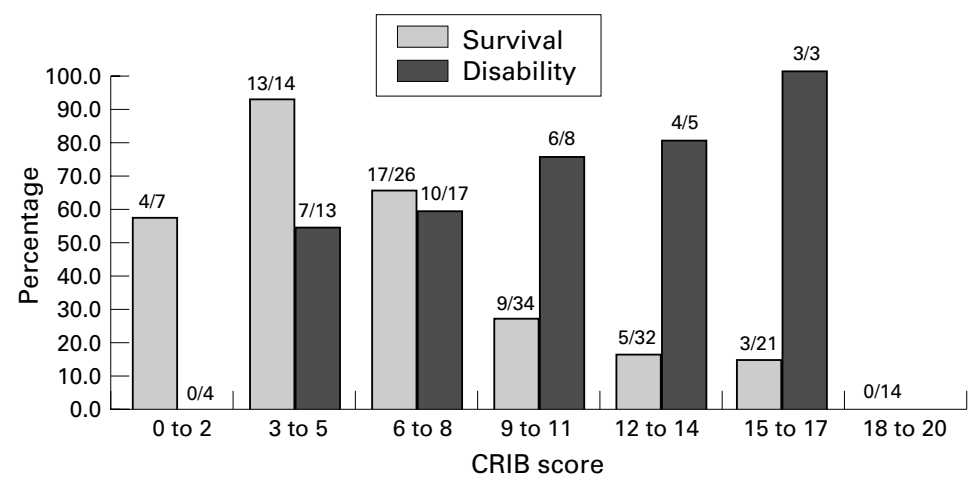

Figure 2 Survival to discharge and disability according to CRIB score.

Table 4 Outcome in later childhood

\begin{tabular}{|c|c|c|c|}
\hline & $\begin{array}{l}\text { Cohort } 1 \\
(1984-89) n=24\end{array}$ & $\begin{array}{l}\text { Cohort } 2 \\
(1990-94) n=40\end{array}$ & $\begin{array}{l}\text { Total (1984-94) } \\
n=64\end{array}$ \\
\hline \multicolumn{4}{|l|}{ Major impairments: } \\
\hline Cerebral palsy & $5(21 \%)$ & $7(18 \%)$ & $12(19 \%)$ \\
\hline Blindness due to ROP & $1(4 \%)$ & $7(18 \%)$ & $8(13 \%)$ \\
\hline Developmental delay, $\mathrm{DQ}<70$ & $3(13 \%)$ & $6(15 \%)$ & $9(14 \%)$ \\
\hline Deafness & $2(8 \%)$ & $1(3 \%)$ & $3(5 \%)$ \\
\hline Epileptic seizures & $1(4 \%)$ & $0(-)$ & $1(2 \%)$ \\
\hline \multicolumn{4}{|l|}{ Minor impairments: } \\
\hline Speech delay & $5(21 \%)$ & $6(15 \%)$ & $11(17 \%)$ \\
\hline Myopia & $1(4 \%)$ & $6(15 \%)$ & $7(11 \%)$ \\
\hline Squint & $2(8 \%)$ & $5(13 \%)$ & $7(11 \%)$ \\
\hline Mild visual impairment due to ROP & $2(8 \%)$ & $2(5 \%)$ & $4(6 \%)$ \\
\hline $\begin{array}{l}\text { Clumsy, learning difficulties and } \\
\text { behavioural disorder }\end{array}$ & $2(8 \%)$ & $1(3 \%)$ & $3(5 \%)$ \\
\hline \multicolumn{4}{|l|}{ Disability: } \\
\hline Mild & $3(13 \%)$ & $15(38 \%)$ & $18(28 \%)$ \\
\hline Moderate & $5(21 \%)$ & $5(13 \%)$ & $10(16 \%)$ \\
\hline Severe & $1(4 \%)$ & $7(18 \%)$ & $8(13 \%)$ \\
\hline Any & $9(38 \%)$ & $27(68 \%)^{\star}$ & $36(56 \%)$ \\
\hline
\end{tabular}

Levels of significance ${ }^{\star} \mathrm{p}<0.05 . \mathrm{DQ}=$ Development Quotient.
Obstetric, neonatal, and outcome data were tabulated against birth era and compared using a $\chi^{2}$ test (or Fisher's test) for categorical variables and a $t$ test for continuous variables, respectively. Due to the small number of 23 week gestational age infants these were considered with the 24 week infants for the statistical analysis. The variables that were associated with survival to discharge and/or disability (mild, moderate, or severe) were analysed using a $\chi^{2}$ test, or a $t$ test, as appropriate. Logistic regression analysis was performed, selecting only those variables already found to be associated with survival and/or disability, and stepwise regression was performed to distinguish those variables most highly correlated with outcome.

\section{Results}

Table 2 shows that the mean birthweight and the mean gestational age were lower in cohort 2 as there were more 23 and 24 week gestational age infants than those of 25 weeks gestation. In cohort $138(40 \%)$ of 96 infants had a gestational age of 23 and 24 weeks, while in cohort $259(61 \%)$ of 96 infants had a similar gestational age (fig 1). Cranial ultrasound scans were carried out in $75(78 \%)$ infants in cohort 1 and $76(79 \%)$ infants in cohort 2 (table 2). There was a higher proportion of clinically significant cranial ultrasound abnormalities in cohort $1(59 \%)$ than in cohort $2(40 \%)$. Before 1990 antenatal steroids (dexamethasone) were not administered to these mothers and none of their infants received artificial surfactant. From 1990 onwards dexamethasone was administered to the mothers of $22(23 \%)$ infants and $52(54 \%)$ infants received surfactant (table 2).

0verall, 66 (34\%) of 192 infants survived. A higher proportion of infants in cohort 2 survived to be discharged than in cohort 1 $(42 \%$ vs $27 \%$; p $<0.05)$ (table 3$)$. Among infants born at 23 and 24 weeks of gestational age, the survival rate was greater in cohort 2 $(20 / 59,34 \%)$ than in cohort $1(7 / 38,18 \%)$ (fig 1). Table 3 shows that the conditions associated with death included a higher percentage of male infants, a lower birthweight, a higher CRIB score and a higher percentage of cranial ultrasound scans with a clinically significant abnormality.

Figure 2 shows that the proportion of survivors discharged from hospital declined with an 
Table 5 Associations with disability in later childhood

\begin{tabular}{|c|c|c|c|c|c|c|}
\hline & \multicolumn{2}{|c|}{ Cohort 1 (1984-89) } & \multicolumn{2}{|l|}{ Cohort 2 (1990-94) } & \multicolumn{2}{|l|}{ Total (1984-94) } \\
\hline & Disability $(n=9)$ & None $(n=15)$ & Disability $(n=27)$ & None $(n=13)$ & Disability $(n=36)$ & None $(n=28)$ \\
\hline \multicolumn{7}{|c|}{ Gestational age (weeks): } \\
\hline 23 & $0(-)$ & $0(-)$ & $2(7 \%)$ & $1(8 \%)$ & $2(6 \%)$ & $1(4 \%)$ \\
\hline 24 & $3(33 \%)$ & $3(20 \%)$ & $14(52 \%)$ & $3(23 \%)$ & $17(47 \%)$ & $6(21 \%)$ \\
\hline 25 & $6(67 \%)$ & $12(80 \%)$ & $11(41 \%)$ & $9(69 \%)$ & $17(47 \%)$ & $21(75 \%)$ \\
\hline Male sex & $5(56 \%)$ & $8(53 \%)$ & $12(44 \%)$ & $6(46 \%)$ & $17(47 \%)$ & $14(50 \%)$ \\
\hline Birthweight & $708.7^{\star}(119.4)$ & $809.9(91.5)$ & $724.0(133.7)$ & $776.6(116.4)$ & $720.2^{\star}(128.8)$ & $795.0(102.8)$ \\
\hline CRIB score & $9.9^{\star}(3.9)(8)$ & $5.9(3.4)(12)$ & $8.6^{\star}(3.5)(22)$ & $5.8(2.9)(8)$ & $8.9^{\star \star}(3.6)(30)$ & $5.9(3.1)(20)$ \\
\hline \multicolumn{7}{|c|}{ Cranial ultrasound findings: } \\
\hline Significant & $3(33 \%)$ & $6(43 \%)$ & $8(32 \%)$ & $1(9 \%)$ & $11(32 \%)$ & $7(28 \%)$ \\
\hline Non-significant & 6 & 8 & 17 & 10 & 23 & 18 \\
\hline
\end{tabular}

Results are numbers of children or mean (SD). Levels of significance ${ }^{\star} p<0.05,{ }^{\star} \mathrm{p}<0.01$. Numbers of observations or percentages are shown in parentheses.

increase in the CRIB score. In the stepwise logistic regression the $\mathrm{p}$ values for variables included in the equation after the final step (those variables included when the highest correct classification was achieved in the regression model) showed that, overall, for the period 1984 to 1994 when forward regression was performed, a higher CRIB score $(p<0.01)$ and clinically significant cranial ultrasound abnormality $(\mathrm{p}<0.0005)$ were associated with death. In cohort 1 forward regression yielded a clinically significant ultrasound abnormality ( $\mathrm{p}$ $<0.005$ ) as having the most significant association with death. In cohort 2 forward regression showed that a higher CRIB score $(p=0.0005)$ was associated with death.

One infant born in 1984 died three months after leaving hospital due to acute cardiac failure and another infant born in 1989 died two months after leaving hospital, attributed to sudden infant death syndrome. The remaining infants in cohort $1(n=24)$ were followed up for 3.3 years to 10.6 years. In cohort $2(n=40)$ three infants born in 1994 were followed up for 19, 20, and 21 months only; the remainder were followed up for 2.2 years to 6.1 years. The findings in both cohorts in later childhood are shown in table 4. A significantly higher proportion of children in cohort 2 than in cohort 1 had a disability $(68 \%$ vs $38 \%$; $\mathrm{p}<0.05)$, but in both these cohorts similar proportions of children had cerebral palsy. In cohort 1, of the five children (21\%) with cerebral palsy, three had diplegia and the remaining two had a hemiplegia. In cohort 2 there were seven children (18\%) with cerebral palsy; four children had diplegia, two had a hemiplegia, and one had a quadriplegia. There were three children $(13 \%)$ with developmental delay in cohort 1 , the DQ (development quotient) was 50 to 69 in two children and $<50$ in one child. In cohort 2 six children $(15 \%)$ had developmental delay, the DQ was 50 to 69 in three children, and $<50$ in the remaining three. These assessments were carried out between 3 and 4 years of age. Blindness due to retinopathy of prematurity, myopia, and squints had contributed to the increase in disability in cohort 2 (table 4 ). No child had cortical blindness.

In 1984-9 the proportion of infants surviving normally was $16 \%$ (15 of 96 infants) of the original population. In 1990-4 the corresponding figure was $14 \%$ (13 of 96 infants).
Survival and disability rates in the two cohorts in relation to gestational age (23 and 24 weeks and 25 weeks) are summarised in fig 1 showing that at 23 to 24 weeks and at 25 weeks survival and disability rates were higher in 1990-4 compared with 1984-9.

Table 5 shows that disability was associated with a lower birthweight and a higher CRIB score. Twenty three $(96 \%)$ of the 24 survivors in cohort 1 and $36(90 \%)$ of 40 survivors in cohort 2 had cranial ultrasound scans. In both cohorts disability was not significantly associated with cranial ultrasound abnormality. No other significant differences were discernible when the gestational age groups were considered separately, or with male sex alone. After stepwise logistic regression, a high CRIB score emerged as the only variable having a significant association with disability for the entire group of survivors between 1984 and 1994 (forward regression $\mathrm{p}=0.0087$ ); it was not significantly associated with the cohorts considered separately. The proportions of children with disability in relation to their CRIB score are shown in fig 2. An increase in the CRIB score is associated with a higher proportion of children with disability.

\section{Discussion}

Although this is not a geographically based study, it has the advantage of detailing a measure of neonatal risk (CRIB score) in a 10 year cohort of extremely preterm infants, covering periods before and after the introduction of antenatal steroid prophylaxis and surfactant therapy. Furthermore, all surviving infants have been followed up and assessed. It is of utmost importance that the pursuit of survival in ever more preterm infants should be tempered by considerations of the likely quality of life in the survivors. Our primary aim was to examine the much debated issue of whether increased survival among infants at the limit of viability is associated with increased disability in later life. This is of particular importance because we have shown an increase in survival of infants born at gestational ages of 23, 24, and 25 weeks ( $27 \%$ in 1984 to 1989 , rising to $42 \%$ in 1990 to 1994 ) and this may have been achieved with changes in obstetric management, resuscitation of infants previously not considered to be viable, and neonatal intensive care. From 1990 onwards antenatal steroid prophylaxis and surfactant were beginning to be used. Surfactant, in particular, was adminis- 
tered selectively only to the sickest infants. The selection of mothers for steroid prophylaxis may have been influenced by the definition of pre-viable gestation which was lowered from 28 weeks of gestation to 23 weeks in 1993 and the provision of neonatal intensive care at such extremes of viability. A lower proportion of our women had therefore received antenatal steroids than in other studies. ${ }^{18}$ Our mortality data for infants of equivalent gestational ages in 1984 to 1989 are broadly similar to those of Cooke $^{18}$ and our more recent data for 1990 to 1994 are also comparable with previous reports. ${ }^{4} 1920$

In spite of the fact that in the later cohort the mean gestational age and birthweight of infants were significantly lower than in the earlier cohort, the survival rate of infants was significantly higher, the apparent improvement applying to infants at $23-24$ weeks and at 25 weeks' gestation. The mean CRIB scores of infants in the two cohorts were similar, implying similar mortality risk. It is therefore possible that infants in the later cohort were less ill, as assessed by the remaining components of the CRIB score, and that planned obstetric care and improved support at birth was beneficial to them. The improved survival rates of the later cohort, however, may have been due, in part, to antenatal steroids and the introduction of surfactant therapy. ${ }^{18}$

Although the mean CRIB score was similar in the two cohorts, the mean score among those who died before discharge from the neonatal unit was significantly higher compared with the survivors, confirming the results of other studies. ${ }^{11}$ Although brain ultrasound scans were not carried out on all our infants (because some infants died before intended scans), our data none the less show that the positive association of significant brain ultrasound abnormalities with mortality before discharge was a feature of both the pre-surfactant and the surfactant era, and applied even though "neonatal risk," as assessed by the CRIB score, was similar in the two cohorts.

Although survival rates were higher in the later cohort, the proportion of infants surviving with any form of disability was significantly higher. However, this was not due to cerebral palsy or developmental delay, but principally blindness due to retinopathy, myopia, and squint. The cause of the retinopathy among extremely preterm infants is unclear and although the affected infants had received oxygen therapy they had all been very carefully monitored to avoid hyperoxaemia. Our data emphasise the need for all neonatal units that undertake the care of extremely preterm infants to have in place a system for regular and skilled retinal examination and access to facilities for retinal ablation therapy. We did not observe a higher proportion of children with clumsiness, specific learning difficulties, or behavioural disorders among children in the later cohort.

Clinically significant abnormal brain ultrasound findings were related to mortality but we did not find such an association among disabled survivors compared with those who survived without any disability. This suggests that an extremely preterm infant with a clinically significant abnormal brain scan is more likely to die than survive with disability. Overall, about a third of surviving children, whether or not disabled, had had clinically significant abnormalities on their brain scans as neonates.

The association between disability and the CRIB score is not surprising and probably reflects the fact that gestational age and birthweight, which contribute to the score, also influence the occurrence of disability. This accords with our observation that the 1990-4 cohort who were less mature had a significantly higher rate of disability.

The rise in disability with improved survival in infants of 23, 24, and 25 weeks of gestational age is an alarming development which, if duplicated elsewhere, may imply that the ethical arguments concerning intensive care should be carefully discussed with parents. Although among survivors the incidence of any severity of disability was significantly higher in the later cohort, a somewhat different picture emerges when the number of normal survivors as a proportion of the original population of live born infants is examined. Here, there was no significant change from 1984-9 compared with $1990-4$ ( $16 \%$ vs $14 \%)$.

In conclusion, in a busy regional referral unit we have admitted and cared for a higher proportion of extremely preterm babies at 23 and 24 weeks of gestation (compared with 25 weeks of gestation) from 1985-9 to 1990-4. This was not reflected in a change in the mean CRIB score and it may well be that infants in the later cohort were in a better condition at birth. Certainly their survival rates had improved. Among survivors, the rate of disability was significantly higher in the later cohort, due mainly to blindness from retinopathy of prematurity, myopia, and squints. None the less, there was no change in the rate of normal survival as a proportion of the live born population.

We thank Dr A J Emmerson and many paediatricians from other hospitals, family doctors, and health visitors who helped with the follow up of children in this study. We are grateful for the helpful suggestions from Professor Boyd. The assistance given to us by Miss Maureen Jones, Miss Anne Hutchinson, Mrs Elaine Evans, Mrs Jean French and Mr Geoffrey Appleton is gratefully acknowledged.

1 Rennie JM. Perinatal management at the lower margin of viability. Arch Dis Child 1996;74: F214-8.

2 Yu VYH, Carse EA, Charlton MP. Outcome of infants born at less than 26 weeks gestation. In: Hansen TN, McIntosh $\mathrm{N}$, eds. Current Topics in Neonatology Number 1. London: W B , eds. Current Topics in Neon

3 Hack M, Fanaroff A. Outcomes of extremely low birthweight infants between 1982 and 1989 . N Engl f Med 1989;321:1642-7.

4 Allen MC, Donohue PK, Dusman AE. The limit of viability - neonatal outcome of infants born at 22 to 25 weeks' gestation. N Engl F Med 1993;329:1597-601.

5 Wariyar U, Richmond S, Hey E. Pregnancy outcome at 24-31 weeks' gestation: neonatal survivors. Arch Dis Child 1989;64:678-86.

6 Johnson A, Townshend P, Yudkin P, Bull D, Wilkinson AR. Functional abilities at 4 years of children born before 29 weeks gestation. BMF 1993;306:1715-8.

7 Whyte HE, Fitzhardinge PM, Shennan AT, Lennox K, Smith L, Lacey J. Extreme prematurity: outcome of 568 pregnancies of 23-26 weeks gestation. Obstet Gynaecol 1993;82:1-7.

8 Cooke RWI. Factors affecting survival and outcome at 3 years in extremely preterm infants. Arch Dis Child 1994;71:F28-31. 
9 Synnes AR, Ling EWY, Whitfield MF, Mackinnon M, Lopes L, Wong G, et al. Perinatal outcomes of a large cohort of extremely low gestational age infants (twenty three to twenty eight comp

10 La Pine TR, Jackson JC, Bennett FC. Outcome of infants weighing less than 800 grams at birth: 15 years experience. Pediatrics 1995;96:479-82

11 The International Neonatal Network. The CRIB (clinical risk index for babies) score: a trial for assessing initial neonatal risk and comparing performance of neonatal intensive care units. Lancet 1993;342:193-8.

12 Scottish Neonatal Consultants' Collaborative Study Group and the International Neonatal Network. CRIB (clinical risk index for babies), mortality and impairment after neonatal intensive care. Lancet 1995;345:1020-2.

13 Walther FJ, Mullett M, Schumacher R, Sundell H, Essa D, Long W and the American Exosurf Neonatal Study Group 1. One-year follow-up of 66 premature infants weighing surfactant or air placebo at birth: Results of a double-blind surfactant or air placebo at birth:
trial. $\mathcal{F}$ Pediatr $1995 ; 126:$ S13-9.

14 Casiro O, Bingham W, MacMurray B, et al, and the Canadian Exosurf Neonatal Study Group and the Canadian Exosurf Neonatal Follow-up Group. One year follow up of 89 infants with birthweights of 500-749 grams and respiratory distress syndrome randomized to two rescue doses of synthetic surfactant or air placebo. 7 Pediatr 1995; 126:553-60.

15 Smyth J, Allen A, Peliowski A, et al and the Canadian Exosurf Neonatal Study Group. Double blind, randomized placebo-controlled Canadian multicentre trial of two doses of synthetic surfactant or air placebo in 224 infants weighing 500 to 749 grams with respiratory distress syndrome. F Pediatr 1995;126:381-9.

16 Griffiths R. Abilities of Babies: A Study in Mental Measurement. London, UK: University Press, 1954.

17 Griffiths R. Abilities of Babies: A Study in Mental Measurement. Norfolk, UK: Lowe and Boydone, 1976.

18 Cooke RWI. Improved outcome for infants at the limits of viability. Eur f Pediatr 1996;155:665-7.

19 Hack M, Horbar JD, Malloy M, Tyson JE, Wright E, Wright L. Very low birthweight outcomes of the National Institute of Child Health and Human Development Neonatal Network. Pediatrics 1991;87:587-9.

20 Hack M, Wright LL, Shankaran S, Tyson JE, Horbar JD, Bauer CR, et al for the National Institute of Child Health
and Human Development National Research Network. Very low birthweight outcomes of the National Institute of Child Health and Human Development Neonatal Network, November 1989-0ctober 1990. Am f Obstet Gynecol work, November 